\title{
Postseismic deformation following the 2005 West Off Fukuoka Prefecture Earthquake (M7.0) derived by GPS observation
}

\author{
Shigeru Nakao ${ }^{1}$, Hiroaki Takahashi ${ }^{2}$, Takeshi Matsushima ${ }^{3}$, Yuhki Kohno ${ }^{3}$, and Masayoshi Ichiyanagi ${ }^{2}$ \\ ${ }^{1}$ Faculty of Science, Kagoshima University, Kagoshima 890-0065, Japan \\ ${ }^{2}$ Institute of Seismology and Volcanology, Graduate School of Science, Hokkaido University, Sapporo 060-0810, Japan \\ ${ }^{3}$ Institute of Seismology and Volcanology, Faculty of Sciences, Kyushu University, Shimabara 855-0843, Japan
}

(Received August 10, 2005; Revised March 13, 2006; Accepted March 16, 2006; Online published February 2, 2007)

\begin{abstract}
We constructed a temporary GPS network around the aftershock area of the 2005 West Off Fukuoka Prefecture Earthquake (M7.0) in order to investigate the characteristics of its postseismic deformation. Our GPS network data, as well as the GEONET data, were analyzed using Bernese GPS software. We detected notable postseismic deformation in horizontal components close to the fault plane. The observed maximum displacement was 5.6 $\mathrm{cm}$ at the GNKI site on Genkaijima Island. A logarithmic law was adapted to the coordinate time series data, revealing decay times from 2 to 23 days, similar to those obtained for the 2003 Tokachi-oki Earthquake (M8.0). The amount of postseismic slips on the fault was assessed using the coseismic fault model proposed by the Geographical Survey Institute (GSI). We derived an optimum fault model of postseismic slip on the shallow (less than $3 \mathrm{~km}$ depth) portion of the fault. Our findings indicate that postseismic slip occurred only in shallow parts of the coseismic fault.
\end{abstract}

Key words: Postseismic deformation, Postseismic slip, 2005 West Off Fukuoka Prefecture Earthquake, GPS.

\section{Introduction}

The 2005 West Off Fukuoka Prefecture Earthquake (M7.0) took place in the northern part of Kyushu, Japan on 20 March 2005. Kato et al. (1998) estimated the strain field for the event from displacement rates at the sites of the nationwide GPS network GEONET and showed that the strain rate in the focal region was no larger than that in the surrounding area. No active faults are known in the source region. However, the NW-SE Kego Fault runs beneath Fukuoka City (The Research Group for Active Faults of Japan, 1991).

Since the 1990s, postseismic deformations have been clearly observed in Japan, following many large interplate (Heki et al., 1997; Takahashi et al., 2004) and intraplate earthquakes (Nakano and Hirahara, 1997; Hashimoto et al., 2003; Matsushima et al., 2005; Takahashi et al., 2005).

There were no GEONET sites near the focal region of the 2005 West Off Fukuoka Prefecture Earthquake, including nearby islands, such stations would have played a key role in constraining models of postseismic deformation. We therefore constructed a dense GPS network, mainly on offshore islands, immediately after the main shock. In this paper we present preliminary results of our analysis of the GPS data with the GEONET data. These results show distinctive postseismic deformation, and we consider a plausible model to explain this deformation.

Copyright (c) The Society of Geomagnetism and Earth, Planetary and Space Sciences (SGEPSS); The Seismological Society of Japan; The Volcanological Society of Japan; The Geodetic Society of Japan; The Japanese Society for Planetary Sciences; TERRAPUB

\section{GPS Stations and Data Analysis}

Ten new GPS sites were deployed immediately after the occurrence of the 2005 West Off Fukuoka Prefecture Earthquake. Figure 1 shows our GPS network together with GEONET sites and epicenters of the main shock and aftershocks determined by the Japan Meteorological Agency (JMA). FOR0 and QUS0 were set up on the day of the main shock while observations at four sites (KTZK, GNKI, SKSM, and NKSM) started on 21 or 22 March 2005. Three additional GPS sites (TKT0, FKN0, and QUAF) were established in the middle of April 2005. Observation at QUAE started after the occurrence of the largest aftershock (M5.8) on 20 April 2005. The four sites deployed during April were located, however, far from the aftershock area, and were therefore not used in the present analysis because of the lack of data for the period immediately after the main shock. We used dual frequency GPS receivers powered by batteries and solar panels at KTZK, GNKI, SKSM, and NKSM, while receivers at other sites used AC powers. GPS antennae were fixed on bolts secured on the roofs of buildings. GPS data were sampled every 30 seconds and stored in the internal memory of the GPS receivers. Some observations were lost at GNKI, NKSM, and SKSM due to power failures, and some were lost at FOR0 due to problems with the GPS receiver.

Bernese GPS software version 5.0 (Hugentobler et al., 2005) was used for the present data analysis combined with IGS (International GPS Service for Geodynamics) precise ephemerides and IERS (International Earth Rotation and Reference Systems Service) Earth rotation parameters (Altamimi et al., 2002). We also used 17 GEONET sites in our analysis. The coordinates of the GEONET sites were 


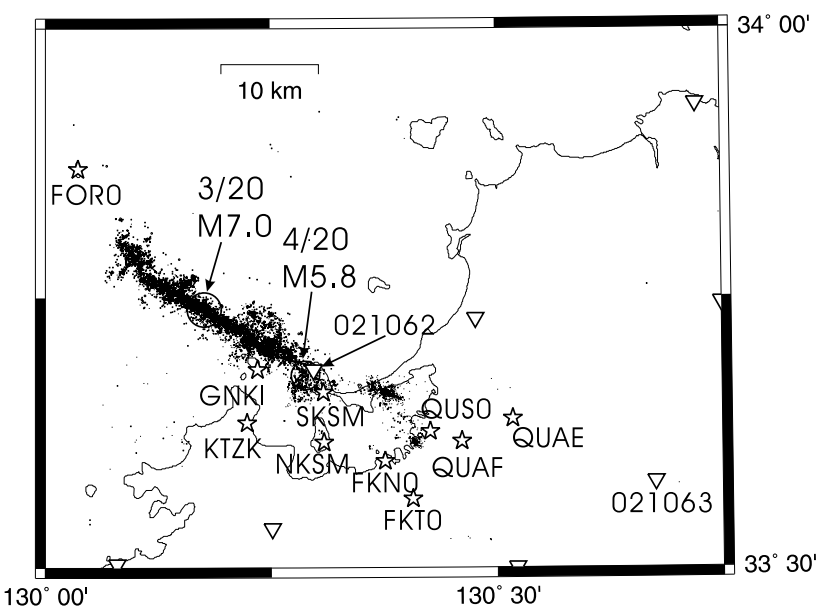

Fig. 1. Location map of GPS sites. Open stars indicate our new GPS sites constructed after the 2005 West Off Fukuoka Prefecture Earthquake. Open triangles show GEONET GPS sites operated by GSI. Black dots and large open circles indicate epicenters of the main shock and aftershocks determined by JMA for the period from 20 March to 20 April 2005.
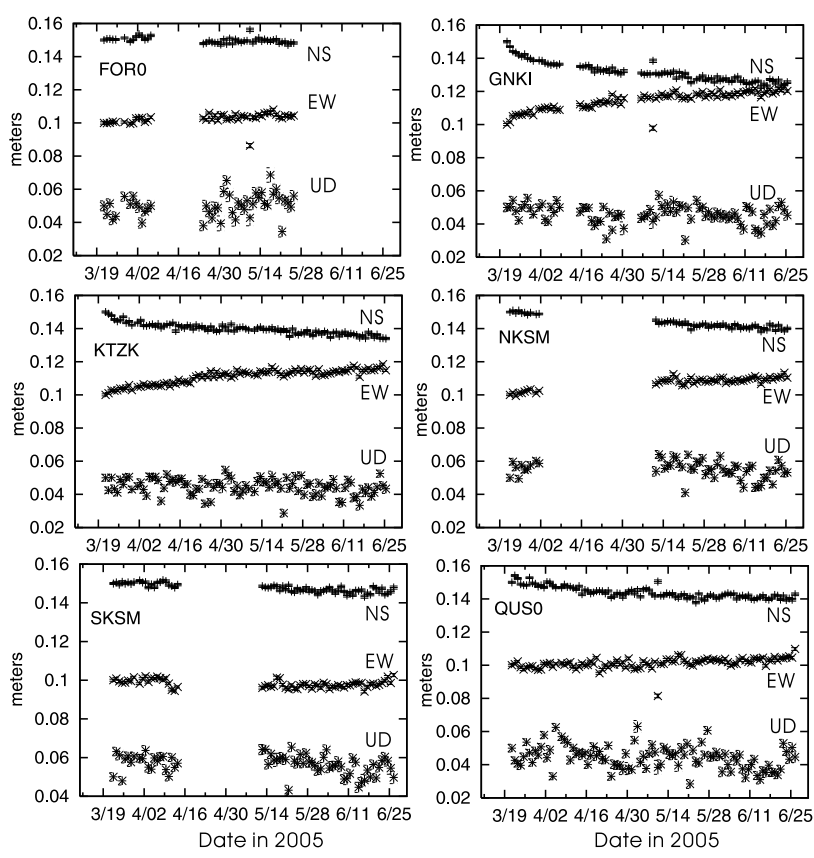

Fig. 2. Northward, eastward and vertical displacement time series data for the GPS sites FOR0, GNKI, KTZK, NKSM, SKSM, and QUS0.

collocated using IGS sites on the International Terrestrial Reference Frame 2000. We then fixed the GEONET site $950388(34.76733 \mathrm{~N}, 131.92314 \mathrm{E})$ as the reference point for this study. The effects of the troposphere were estimated hourly while site coordinates and the effects of the troposphere gradient were estimated every 24 hours.

\section{Results and Discussion}

Figure 2 shows the time series data for GPS sites from 21 March to 27 June 2005. Significant postseismic deformation in horizontal components is clearly seen at GNKI and KTZK, while the GEONET site 021062 shown in Fig. 3 also shows detectable postseismic deformations. The maximum postseismic displacement during this period was 5.6
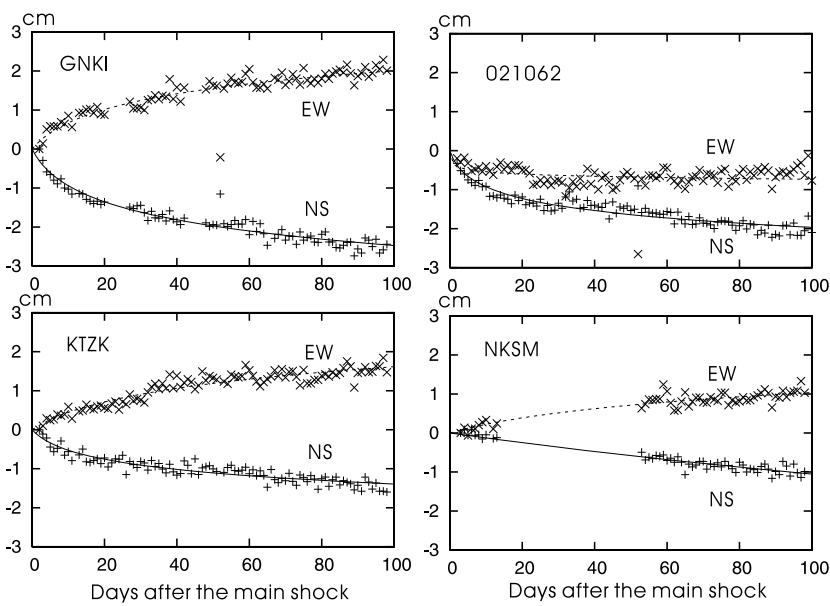

Fig. 3. Northward (NS) and eastward (EW) components of displacements at the GPS sites GNKI, KTZK, NKSM, FOR0, SKSM, and 021062. Fitted logarithmic functions are shown by solid and dashed curves.

$\mathrm{cm}$ at GNKI. In contrast, there were no significant variations in vertical components.

Transient decay of postseismic deformations has been generally modeled by either exponential or logarithmic functions (Donnellan and Lyzenga, 1998). While exponential functions characterize the relaxation of a Maxwell viscoelastic solid, logarithmic functions are based on the theory on rate- and state-dependent friction governing postseismic slips (Marone et al., 1991). Relaxation times of exponential functions by previous studies vary from $0.3-1.4$ years (Donnellan and Lyzenga, 1998) to 50 days (Nakano and Hirahara, 1997). Since record lengths in this study are 97 days and may be too short to evaluate, comparing the previous relaxation times, we did not consider the exponential law. Instead, the logarithmic law is fitted to the present data as follows:

$$
y(t)=a \ln \left(\frac{t}{b}+1\right)
$$

where $t$ is the time in days, and $y(t)$ is the northward or eastward displacement. $a$ is the amplitude of the logarithmic law, and $b$ is the decay time.

Figure 3 shows the time series data of northward and eastward displacements at GNKI, 021062, KTZK, and NKSM along with the fitted logarithmic curves. Although SKSM is located between 021062 and NKSM (Fig. 1), clear logarithmic decays were not evident on either components at this site (Fig. 2). The time series data of FOR0 seem to follow almost a linear function of time rather than the logarithmic law, as shown in Fig. 2. FOR0 was located in the region with small horizontal displacements expected from a coseismic strike-slip faulting. Then, the postseismic displacement at FOR0 may also be small if the postseismic slips occurred on the same fault. Estimated decay times of northward and eastward components are 2-5 days and 6-23 days, respectively, where decay times of the northward component at NKSM (191 days) and the eastward component at 021062 (0.02 days) were excluded because these times were much longer and much shorter, respectively, than those at other sites. 

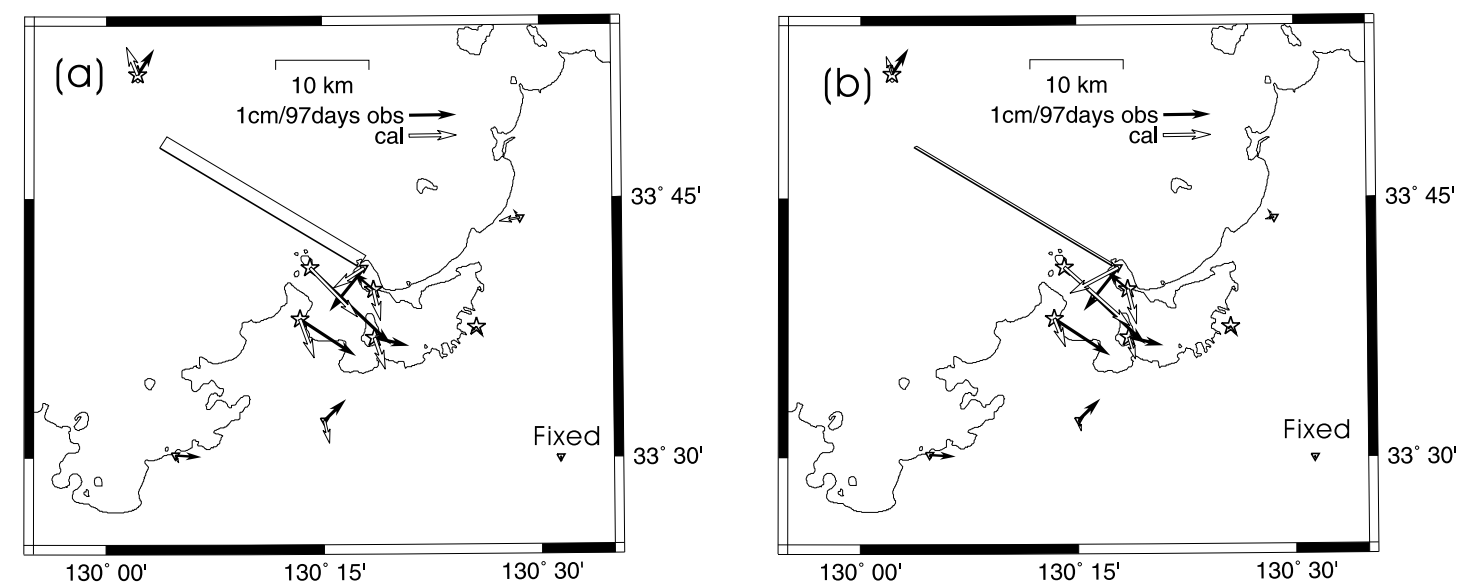

Fig. 4. Observed postseismic deformation from 21 March to 25 June 2005 (solid arrows). Open stars and open triangles show temporary and GEONET GPS sites, respectively. (a) Open arrows indicate deformation calculated from the GSI fault model with the estimated slip shown in Model A (Table 1). (b) Open arrows indicated deformation calculated from the shallower fault model, Model B in Table 1.

Table 1. Fault parameters of coseismic and postseismic slips.

\begin{tabular}{cccccccccc}
\hline & $\begin{array}{c}\text { Latitude* } \\
\text { (degrees) }\end{array}$ & $\begin{array}{c}\text { Longitude* } \\
(\text { degrees })\end{array}$ & $\begin{array}{c}\text { Depth** } \\
(\mathrm{km})\end{array}$ & $\begin{array}{c}\text { Strike } \\
(\text { degrees })\end{array}$ & $\begin{array}{c}\text { Dip } \\
(\text { degrees })\end{array}$ & $\begin{array}{c}\text { Length } \\
(\mathrm{km})\end{array}$ & $\begin{array}{c}\text { Width } \\
(\mathrm{km})\end{array}$ & $\begin{array}{c}\text { Slip } \\
(\mathrm{cm})\end{array}$ & $\begin{array}{c}\text { Rake } \\
(\text { degrees })\end{array}$ \\
\hline GSI's model (GSI, 2005) & 33.7401 & 130.1798 & 0.0 & 301 & 85 & 23.9 & 16.3 & 70 & 1 \\
Model A & 33.7401 & 130.1798 & 0.0 & 301 & 85 & 23.9 & 16.3 & $4.8 \pm 0.91$ & 0 \\
Model B & 33.7401 & 130.1798 & 0.0 & 301 & 85 & 23.9 & 3.0 & $9.3 \pm 1.53$ & 0 \\
\hline
\end{tabular}

*Position of the midpoint of the fault length.

** Depth of the upper extent of the fault plane.

The estimated decay times of 2 to 23 days are similar to those estimated by Takahashi et al. (2005) and Matsushima et al. (2005) for the 2004 mid-Niigata Prefecture Earthquake (M6.8); these studies adopted the same logarithmic law as that used in the present study. The mid-Niigata Prefecture Earthquake was also an inland shallow earthquake, similar to the 2005 West Off Fukuoka Prefecture Earthquake. This indicates that the overall mechanism of postseismic slips may be common for this type of earthquakes. Takahashi et al. (2004) also analyzed the postseismic deformation associated with the 2003 Tokachi-oki Earthquake (M8.0), a large thrust event in a subduction zone along the Kuril Trench with the logarithmic law; their estimated decay times (4-11 days) are also similar to those of the present study. This agreement in decay times may suggest that the temporal characteristics of postseismic slips are similar, even for interplate and inland earthquakes at least, in terms of the logarithmic law.

The horizontal vectors of the postseismic deformations from 21 March to 25 June 2005 are shown in Fig. 4 by solid arrows, with the GEONET site 950451 as the reference. The direction of postseismic deformation at 021062 is quite similar to the observed coseismic deformation shown in Fig. 5 (GSI, 2005). Fault parameters of the GSI's model are listed in Table 1. A simple single fault model is used, although Uehira et al. (2006) estimated a fault geometry of the main shock using precise aftershock distribution. Coseismic deformations at our GPS sites calculated using the GSI's fault model (GSI, 2005) with the Green functions obtained by Okada (1992) are also similar to those of the post-

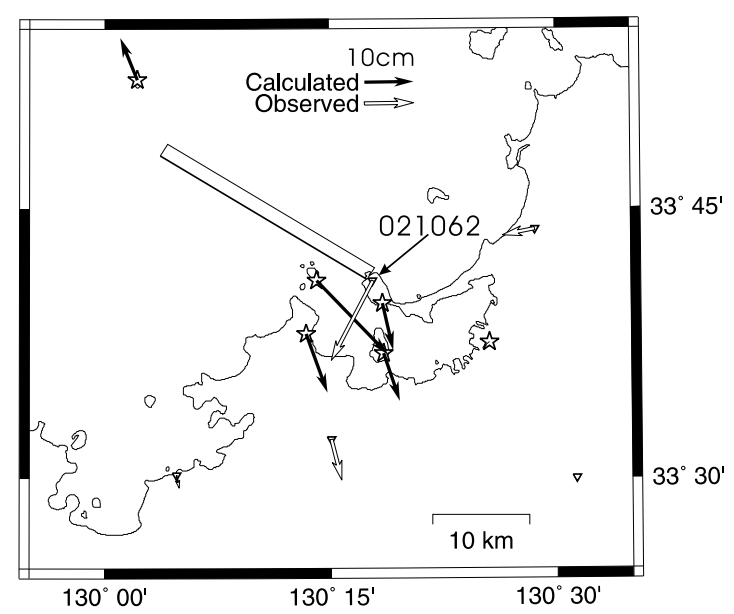

Fig. 5. Observed and calculated coseismic deformation. White arrows indicate the observed coseismic deformation at GEONET sites. Black arrows indicate the calculated coseismic deformation at our temporary sites, based on the GSIfs fault model (GSI, 2005) and fault parameters listed in Table 1.

seismic deformations, as shown in Fig. 5. This suggests that the observed postseismic deformation in this study follows the same fault plane and slips of the main shock. Postseismic deformation at 021062 can be explained by $4.8 \mathrm{~cm}$ of postseismic slips on the entire GSI fault model (Model A in Table 1) using the least-squares method (LSM); this represents about $6.9 \%$ of the coseismic slip. Postseismic slips of the Model A were assumed strike slips because strike slips 


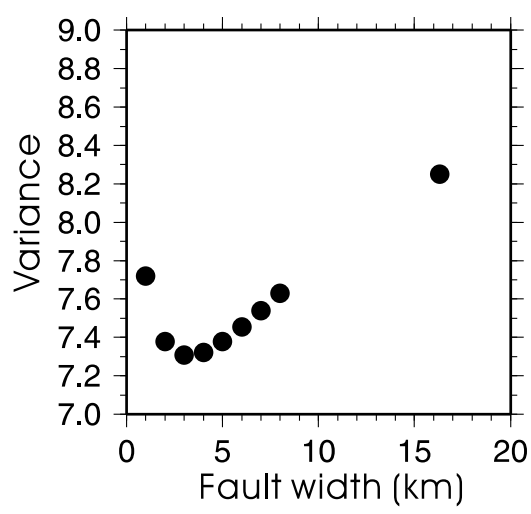

Fig. 6. Variance versus fault width assumed for the least-squares estimation of postseismic slip (see text for details).

of the GSI model for the main shock are dominant.

Marone et al. (1991) proposed a logarithmic formula for postseismic slips based on a model in which postseismic slips occur only on shallower regions of the coseismic fault. We attempted to estimate areas on the coseismic fault where postseismic slips were localized. We varied the fault width from 1 to $8 \mathrm{~km}$ at $1 \mathrm{~km}$ intervals and $16.3 \mathrm{~km}$, fixing the other fault geometries (Model B in Table 1). Postseismic slips of the Model B were also assumed to be strike slips. Postseismic slips for each width value were estimated by LSM and squared variances are shown in Fig. 6. From these calculation, we derived an optimum fault width of $3 \mathrm{~km}$. Comparison between displacements estimated from the best fit model and observed ones is shown in Fig. 4(b). The postseismic slip on the fault amounts to $9.3 \mathrm{~cm}$, about $13 \%$ of the coseismic slip. This model (Model B in Table 1) clearly shows a better fit than Model A (displacements shown in Fig. 4(a)), suggesting that the postseismic slip occurred only on a shallower part of the coseismic fault. Nishimura et al. (2006) found that large coseismic slips were concentrated on the shallower part (depths of 0 to 10 $\mathrm{km}$ ) of the fault using GPS and InSAR data. The postseismic slip area corresponds in position to the shallower part of the large coseismic slip area.

\section{Conclusion}

We constructed a new dense GPS network in the aftershock area of the 2005 West Off Fukuoka Prefecture Earthquake immediately after the main shock and analyzed data from the temporary sites together with those of GEONET. We found notable postseismic deformations in coordinate time series data which obey logarithmic functions. The characteristic decay time is 2-23 days, similar to that of the past interplate and shallow inland earthquakes. We also obtained an optimum fault model with a width of $3 \mathrm{~km}$, to explain the observed postseismic deformations. This suggests that the postseismic slips were localized in a shallower part of the coseismic fault.
Acknowledgments. We thank the Kitazaki, Shikanoshima, and Noko Primary schools, Genkaishima Fishermen's Cooperative Association, and Faculty of Agriculture, Kyushu University, for giving us permission to install GPS receivers. The Geographical Survey Institute provided GEONET GPS data. We are thankful to S. Miura and an anonymous reviewer for their constructive comments. A GMT software package (Wessel and Smith, 1995) was used to draw the figures in this paper.

\section{References}

Altamimi, Z., P. Sillard, and C. Boucher, ITRF2000: A new release of International Terrestrial Reference Frame for earth science applications, J. Geophys. Res., 107, doi:10.1029/2001JB000561, 2002.

Donnellan, A. and G. A. Lyzenga, GPS observations of fault afterslip and upper crustal deformation following the Nothridge earthquake, $J$. Geophys. Res., 103, 21285-21297, 1998.

Geographical Survey Institute, The fault model of the West Off Fukuoka Prefecture Earthquake, http://www.jishin.go.jp/main/chousa/ 05mar_fukuoka/p17.gif, 2005

Hashimoto, M., T. Tabei, T. Sagiya, and T. Ito, A model for the postseismic deformation following the 2000 western Tottori Earthquake (Revised), Abstract Seism. Soc. Jpn., C099, 2003.

Heki, K., S. Miyazaki, and H. Tsuji, Silent fault slip following an interplate thrust earthquake at the Japan Trench, Nature, 386, 595-598, 1997.

Hugentobler, U., R. Dach, and P. Fredez, Bernese GPS Software Version 5.0, AIUB, 392 pp., 2005.

Kato, T., G. S. EL-Fiky, and E. N. Oware, Crustal strains in the Japanese islands as deduced from dense GPS array, Geophys. Res. Lett., 25, 3445-3448, 1998.

Marone, C. J., C. H. Scholtz, and R. Bilham, On the mechanics of earthquake afterslip, J. Geophys. Res., 96, 8441-8452, 1991.

Matsushima, T., H. Takahashi, T. Kato, A. Takeuchi, T. Yamaguchi, Y. Kohno, J. Fukuda, K. Hatamoto, R. Doke, Y. Matsu'ura, and M. Kasahara, Postseismic deformation of the 2004 Niigata-Chuetsu earthquake (M6.8) by a dense GPS observation, Abstracts 2005 Japan Earth and Planetary Science Joint Meeting, S101-P012, 2005.

Nakano, T. and K. Hirahara, GPS observations of postseismic deformation for the 1995 Hyogo-ken Nanbu earthquake, Japan, Geophys. Res. Lett., 24, 503-506, 1997.

Nishimura, T., S. Fujiwara, M. Murakami, H. Suito, M. Tobita, and H. Yarai, Fault model of the 2005 Fukuoka-ken Seiho-oki earthquake estimated from coseismic deformation observed by GPS and InSAR, Earth Planets Space, 58, 51-56, 2006.

Okada, Y., Internal deformation due to shear and tensile faults in a halfspace, Bull. Seismol. Soc. Am., 82, 1018-1040, 1992.

The Research Group for Active Faults of Japan, Active Faults in Japan, revised edition, University of Tokyo Press, 437 pp., 1991.

Takahashi, H., S. Nakao, N. Okazaki, J. Koyama, T. Sagiya, T. Ito, F. Ohya, K. Sato, Y. Fujita, M. Hashimoto, Y. Hoso, T. Kato, T. Iinuma, J. Fukuda, T. Matsushima, Y. Kohno, and M. Kasahara, GPS observation of the first month of postseismic crustal deformation associated with the 2003 Tokachi-oki earthquake $\left(\mathrm{M}_{J M A}\right.$ 8.0), off southeastern Hokkaido, Japan, Earth Planets Space, 56, 377-382, 2004.

Takahashi, H., T. Matsushima, T. Kato, A. Takeuchi, T. Tamaguchi, Y. Kohno, T. Katagi, J. Fukuda, K. Hatamoto, R. Doke, Y. Matsu'ura, and M. Kasahara, A dense GPS observation immediately after the 2004 midNiigata prefecture earthquake, Earth Planets Space, 57, 661-665, 2005.

Uehira, K. ,T. Yamada, M. Shinohara, K. Nakahigashi, H. Miyamachi, Y. Iio, T. Okada, H. Takahashi, N. Matsuwo, K. Uchida, T. Kanazawa, and H. Shimizu, Precise aftershock distribution of the 2005 West Off Fukuoka Prefecture Earthquake $(\mathrm{Mj}=7.0)$ using a dense onshore and offshore seismic network, Earth Planets Space, 58, this issue, 16051610, 2006.

Wessel, P. and W. H. F. Smith, New Version of the Generic Mapping Tools Released, EOS Trans. AGU, 76, 329, 1995.

S. Nakao (e-mail: nakao@sci.kagoshima-u.ac.jp), H. Takahashi, T. Matsushima, Y. Kohno, and M. Ichiyanagi 